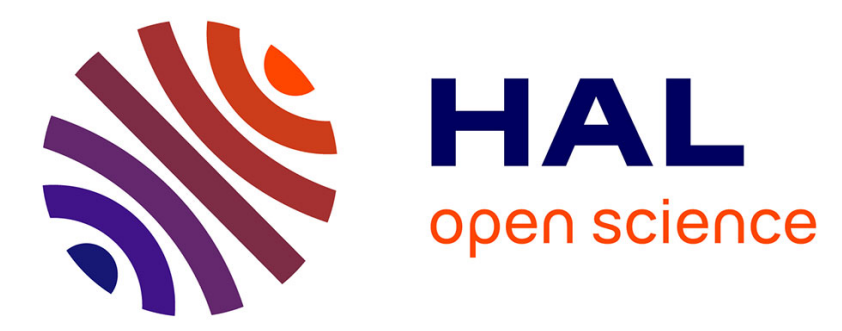

\title{
Complex elastic properties and piezoelectric activity in stoichiometric and congruent LiNbO3 single crystals
}

\author{
Iwona Franke, Jean-Paul Salvestrini, Marc Fontana, Krystian Roleder
}

\section{To cite this version:}

Iwona Franke, Jean-Paul Salvestrini, Marc Fontana, Krystian Roleder. Complex elastic properties and piezoelectric activity in stoichiometric and congruent LiNbO3 single crystals. Ferroelectrics, 2004, 304 (1), pp.155-158. 10.1080/00150190490457843 . hal-00186020

\section{HAL Id: hal-00186020 \\ https://hal.science/hal-00186020}

Submitted on 3 Dec 2021

HAL is a multi-disciplinary open access archive for the deposit and dissemination of scientific research documents, whether they are published or not. The documents may come from teaching and research institutions in France or abroad, or from public or private research centers.
L'archive ouverte pluridisciplinaire HAL, est destinée au dépôt et à la diffusion de documents scientifiques de niveau recherche, publiés ou non, émanant des établissements d'enseignement et de recherche français ou étrangers, des laboratoires publics ou privés.

\section{다)(1) $(5$}

Distributed under a Creative Commons Attribution - NonCommerciall 4.0 International 


\title{
Complex Elastic Properties and Piezoelectric Activity in Stoichiometric and Congruent $\mathrm{LiNbO}_{3}$ Single Crystals
}

\author{
IWONA FRANKE \\ Institute of Physics \\ University of Silesia \\ ul. Uniwersytecka 4, 40-007 Katowice, Poland \\ JEAN-PAUL SALVESTRINI \\ MARC FONTANA \\ MOPS Laboratory, FRE CNRS 2304 \\ University of Metz and Supelec \\ 2 rue E. Belin, 57-078 Metz, France

\section{KRYSTIAN ROLEDER} \\ Institute of Physics \\ University of Silesia \\ ul. Uniwersytecka 4, 40-007 Katowice, Poland
}

\begin{abstract}
Piezoelectric effect has been measured for stoichiometric ( $\mathrm{Li} / \mathrm{Li}+\mathrm{Nb}=50 \mathrm{~mole} \%)$ and congruent $(\mathrm{Li} / \mathrm{Li}+\mathrm{Nb}=48.6$ mole\%) lithium niobate crystals. Observations of the piezoelectric resonance allowed to investigate the temperature dependence of the complex elastic coefficient $s^{*} 11$. Distinct local maxima on the $s_{11}^{\prime \prime}(T)$ dependencies have been found.
\end{abstract}

Keywords Piezoelectricity; complex elastic constant; lithium niobate

\section{Introduction}

Progress made in crystal-growth techniques enables a better control of chemical composition of $\mathrm{LiNbO}_{3}$ crystals [1] which are widely used in electro-optics [2] and which properties strongly depend on their stoichiometry. In the electrooptical effect the piezoelectricity plays an essential role [3]. Temperature behaviour of piezoelectric deformation can however be influenced by crystal imperfections. By piezoelectric resonance observations the elastic properties of samples could be directly determined.

Address correspondence to Iwona Franke, Institute of Physics, University of Silesia ul., Uniwersytecka 4, Katowice 40-007, Poland. E-mail: ifranke5@us.edu.pl 


\section{Experimental Conditions}

The absolute admittance $/ Y_{c} /$ and phase angle $\theta$ were measured in the function of frequency by means of a Hewlett-Packard 4192A Impedance Analyser. The $/ Y_{c} /$ was fitted with the relation

$$
\left|Y_{c}(\omega)\right|=\sqrt{G_{c}^{2}(\omega)+B_{c}^{2}(\omega)},
$$

in which the mathematical form of the total conductance $G_{c}=/ Y_{c} / \cos \theta$ and susceptance $B_{c}=/ Y_{c} / \sin \theta$ has been derived basing on the theory of forced damped harmonic oscillator with complex amplitude. Under the action of the external electric field of frequency $\omega$ the $G_{c}(\omega)$ and $B_{c}(\omega)$ near the piezoelectric resonance obey the following relations:

$$
G_{c}(\omega)=A \cdot \frac{\omega^{2} \Gamma}{\left(\omega_{0}^{2}-\omega^{2}\right)^{2}+\omega^{2} \Gamma^{2}}+G \quad B_{c}(\omega)=A \cdot \frac{\omega \cdot\left(\omega_{0}^{2}-\omega^{2}\right)}{\left(\omega_{0}^{2}-\omega^{2}\right)^{2}+\omega^{2} \Gamma^{2}}+\omega C_{d}^{\prime}
$$

In which $A$ is a constant value connected with sample geometry, amplitude of external electric field and piezoelectric and elastic coefficients. The $G$ and $C_{d}^{\prime}$ are related with dielectric properties of the sample far behind the piezoelectric resonance. Example of a fit representing model applicability is shown in Fig. 1. Having the resonance frequency $f_{0}=2 \pi / \omega_{0}$, damping $\gamma_{0}=2 \pi / \Gamma$, length $l$ and density $\rho$ of a sample the complex elastic coefficient $s=s^{\prime}-i s^{\prime \prime}$ could be calculated from the relation $s^{E}=s^{\prime} E-i s^{\prime \prime} E=$ $\frac{1}{4 \rho l^{2} f_{0}^{2}}-i \frac{1}{4 \rho l^{2} f_{0}^{2}}\left(\frac{\gamma}{f_{0}}\right)$.

The stoichiometric and congruent $\mathrm{LiNbO}_{3}$ were grown by the TSSG and Czochralski method respectively [1]. According to geometrical conditions needed for coefficient $s_{11}^{E}$ assignment, samples of bar shape were cut from single domain single crystals. The largest surfaces perpendicular to c-axis were electroded by gold evaporation. Temperature dependence of the complex elastic constant has been measured in the temperature range $20-180^{\circ} \mathrm{C}$.
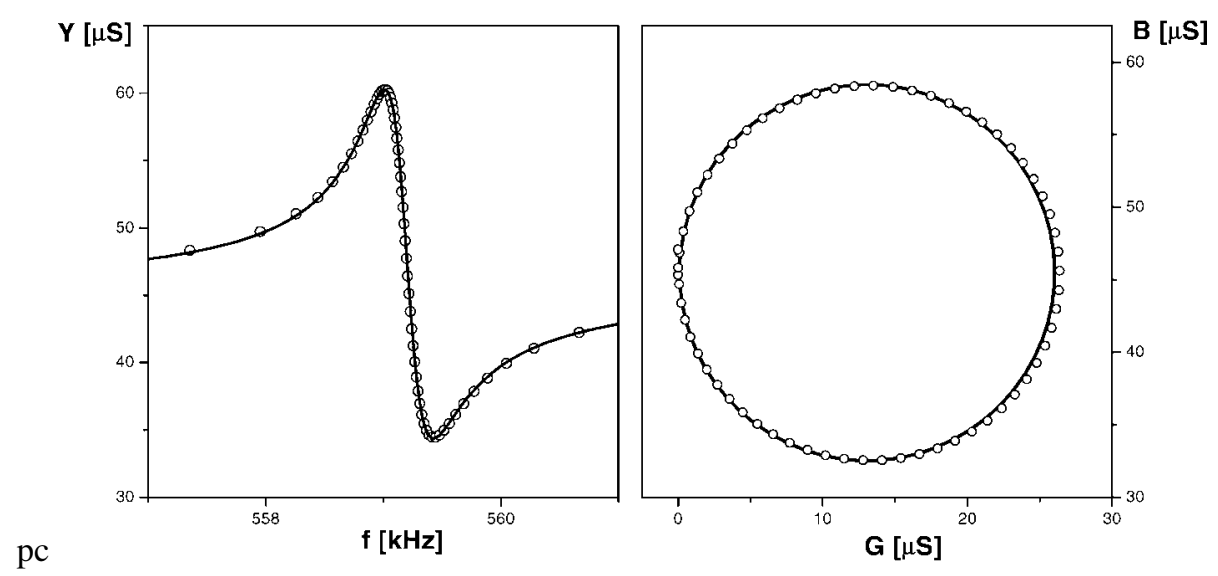

FIGURE 1 Simultaneous fit with theoretical functions (1) and (2) to the experimental run $/ Y_{c} /(\omega)$ at room temperature. Separate fits for the $G_{c}(\omega)$ and $B_{c}(\omega)$ are shown in complex plane. Elastic constant $s_{11}^{\prime E}$ and piezoelectric module $/ d_{31} /$ calculated from the data were equal respectively to $5,6 \cdot 10^{-12} \mathrm{~m}^{2} / \mathrm{N}$ and $0.84 \cdot 10^{-12} \mathrm{~m} / \mathrm{V}$. 


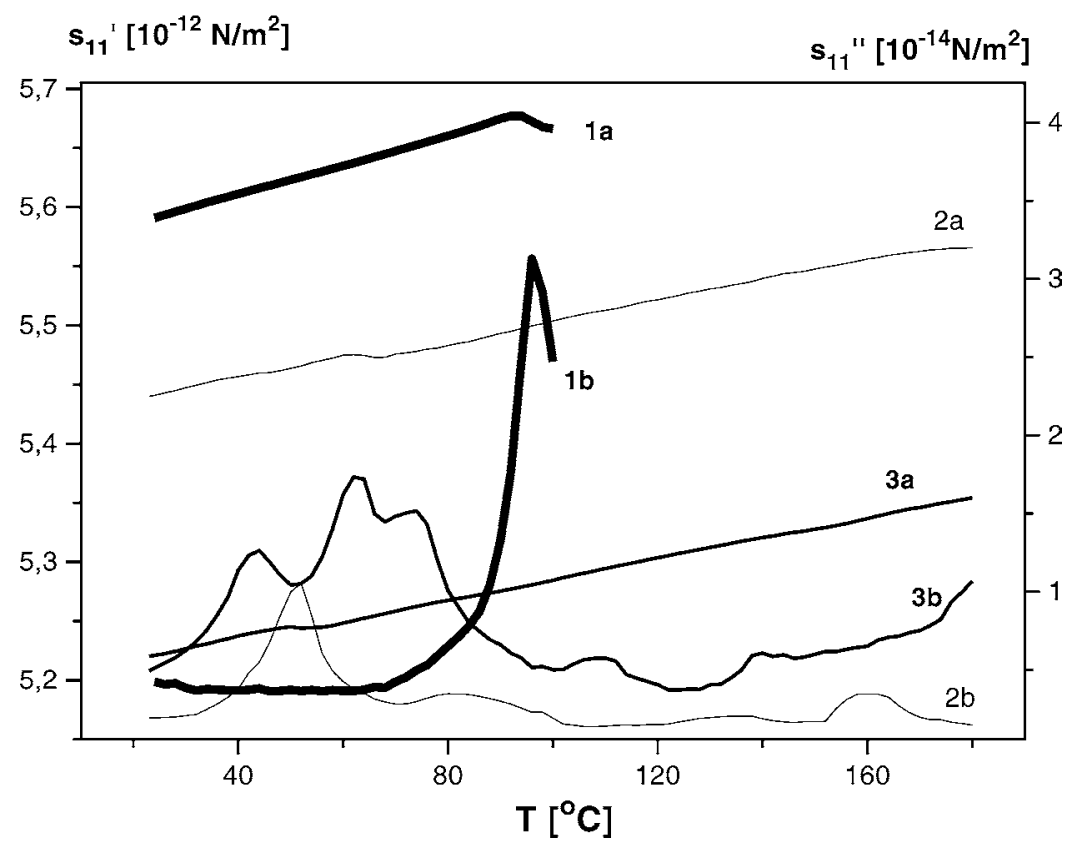

FIGURE 2 Temperature behaviour of real $s_{11}^{\prime E}$ (curves "a") and imaginary $s_{11}^{\prime E}$ part (curves "b") of the elastic coefficient for two stoichiometric (curves 1,2) and one congruent (curves 3) $\mathrm{LiNbO}_{3}$ single crystals.

\section{Results and Conclusions}

Changes of the real and imaginary part of $s_{11}$ with temperature are shown in Fig. 2. While real parts (curves 1a, 2a, 3a) smoothly increased the $s^{\prime \prime}{ }_{11}(T)$ runs (curves 2a, 2b, 3b) revealed distinct local maxima at particular temperatures. The number and intensity of those maxima depended on crystal stoichiometry and number of thermal cycles (heating-cooling). It was found that the cycles made between $25^{\circ} \mathrm{C}$ and $70^{\circ} \mathrm{C}$ did not change the elastic properties of the samples: in one of the stoichiometric crystals there was only single, but distinct, local maximum of the $\mathrm{s}^{\prime \prime}{ }_{11}(T)$ function (curve $1 \mathrm{~b}$ ). If final temperature on heating was higher than $70^{\circ} \mathrm{C}$ the observed maxima in both samples shifted towards lower temperatures with increasing number of thermal cycles. Since imaginary part of elastic tensor is related with damping of lattice vibrations induced by external forces the appearance of the $\mathrm{s}^{\prime \prime}{ }_{11}(T)$ peaks might be related with local absorption of elastic energy due to defects. It is suggested that the effects observed in lithium niobate were caused by defect migration because of the exo-diffusion of $\mathrm{Li}^{+}$ions as considered by Ridah et al. [4].

\section{Acknowledgement}

Authors are grateful to Dr S. Miga for discussions and writing experimental software.

\section{References}

1. K. Polgar, A. Peter, L. Kovacs, G. Corradi, and Z. Szaller, Growth of stoichiometric $\mathrm{LiNbO}_{3}$ single crystals by top seeded solution growth method. J. Cryst. Growth 177, 211-216 (1997).

2. T. Fujiwara, M. Takahashi, M. Ohama, A. J. Ikushima, Y. Furukawa, and K. Kitamura, Comparison of electrooptic effect between stoichiometric and congruent $\mathrm{LiNbO}_{3}$. Electronic Letters 35, 499-500 (1999). 
3. F. Abdi, M. Aillerie, P. Bourson, M. D. Fontana, and K. Polgar, Electro-optic properties in pure $\mathrm{LiNbO}_{3}$ crystals from the congruent to the stoichiometric composition. J. Appl. Phys. 84, 2251-2254 (1998).

4. A. Ridah, M. D. Fontana, P. Bourson, and G. Malovichko, The composition dependence of the Raman spectrum and new assignment of the phonons in $\mathrm{LiNbO}_{3}$. Journal of Physics: Condensed Matter 9, 9687-9693 (1997). 